\title{
Equal partnership to ensure that developing countries benefit from genomics
} nfectious diseases pose a great threat to
the economic survival of the poorest developing countries-each 10\% improvement in life expectancy at birth is thought to be associated with a rise in economic growth of at least $0.3-0.4 \%$ per year ${ }^{1}$. Yet, the bulk of genomics research is not directed at these diseases, owing to the brutal reality that research is largely driven by market forces-its products are probably unaffordable to the poor living in the developing countries ${ }^{2}$. This discrepancy risks the creation of a 'genomics divide' between rich and poor countries ${ }^{3}$, such that $90 \%$ of those suffering from health problems will not benefit from what is arguably the most golden era of biology and medicine.

Will advances in genomics actually improve health in developing countries? What do personalized medicine and gene therapy mean to one-third of the world's population, who live on less than $\$ 2$ per day? Probably not very much. Some believe, in fact, that genomics has diverted precious resources away from the core issues of global public health, such as provision of clean water, safe food, proper sewage disposal, decent housing and access to maternal and child care ${ }^{4}$.

What steps can be taken to avoid creating this genomics divide? In response to a report from the World Health Organiza- tion on Genomics and World Health ${ }^{2}$, a panel of international experts, including many from developing countries, recently ranked the top ten biotechnologies most likely to impact global health in the next $5-10$ years $^{5}$. This is a step in the right direction, but it must be accompanied by a genuine willingness on the part of the developed countries and the pharmaceutical and biotechnology industries to share knowledge and help poorer countries apply such knowledge to solving their health problems: "[w]hat can First World science do, not for the West, but for the rest..."6. The developed world must also be prepared to invest more money in research in developing countries ${ }^{7}$, but this must be done in the spirit of helping developing countries ultimately to help themselves. Only thus will such investments be sustainable and equitable and a genomics divide avoided.

What mechanisms can be put in place to achieve this objective? Some have suggested that we create "an international commission to govern the application of biotechnology" so that it is consistent with "local values" 5 . Is this the answer? Perhaps; but more discussion seems warranted. An initiative originating in the developed world in the form of (yet) another 'international' commission, with token participation from a few scientists from developing countries, may not be the best road forward. A more acceptable approach would be to truly involve and empower scientists and institutions in developing countries, working together in equal partnership. Partners could include newly formed regional groupings such as the Asia-Pacific Health Research Forum and the African Health Research Forum. An international initiative should also involve scientists and institutions from the more genomically advanced developing countries-Brazil, India, China, Malaysia and Thailand have made significant inroads and are shining examples of national commitment to the potential of genomics. Involvement of the Third World Academy of Science will also signal true empathy with the role of science in helping to solve health problems of the developing world. At the beginning of the new millennium, it is apparent that developing countries should participate in managing their own futures, and thus be invited to work together in equal partnership toward a healthier world.

Tikki Pang

Research Policy \& Cooperation, World Health Organization, Avenue Appia, CH-1211, Geneva 27, Switzerland. e-mail: pangt@who.int

1. Report of the Commission on Macroeconomics and Health (World Health Organization, Geneva, 2001).

2. Genomics and World Health: A Report from the Advisory Committee on Health Research (World Health Organization, Geneva, 2002).

3. Singer, P. \& Daar, A. Science 294, 87-89 (2001).

4. Garrett, L. Betrayal of Trust-The Collapse of Global Public Health (Hyperion, New York, 2001).

5. Daar, A. et al. Nat. Genet. 32, 229-232 (2002).

6. Kennedy, D. Science 294, 2053 (2001)

7. Sachs, J. New Sci. 175, 52-55 (2002). 